\title{
Immunomodulatory, anti-inflammatory, and antioxidant effects of curcumin
}

\author{
Nadia Boroumand ${ }^{\circledR}$, Saeed Samarghandian ${ }^{2}$, Seyed Isaac Hashemy ${ }^{3 *}$ \\ ${ }^{1}$ Department of Clinical Biochemistry, Faculty of Medicine, Mashhad University of Medical Sciences, Mashhad, Iran \\ ${ }^{2}$ Department of Basic Medical Science, Neyshabur University of Medical Scisnces, Neyshabur, Iran \\ ${ }^{3}$ Surgical Oncology Research Center, Mashhad University of Medical Sciences, Mashhad, Iran
}

\section{AR T I C L E IN F O}

Article Type:

Review

\section{Article History:}

Received: 11 May 2018

Accepted: 9 August 2018

\section{Keywords:}

Immuno-modulation

Anti-inflammation

Antioxidant

Oxidative stress

Curcumin

\begin{abstract}
A B S T R A C T
Turmeric is a widely used spice derived from the rhizomes of Curcuma longa. Having been used as a dietary spice, it has drawn scientists' attention to the possible medicinal benefits of its active compounds called curcuminoids which consist of curcumin, demethoxycurcumin and bisdemethoxycurcmin. Considering wide range of pharmacological properties that curcumin offers, numerous studies have investigated its potency as a therapeutic agent in various diseases such as autoimmune, cardiovascular, neoplastic, pulmonary, neurodegenerative and metabolic diseases. With regard to its wide array of health benefits and published data on the underlying mechanisms of its action, a complex interaction between three main events including inflammation, oxidative stress, and immunity, seems to contribute to different therapeutic roles of this compound. Hence, this review discusses the current knowledge on the anti-inflammatory, antioxidant, and immunomodulatory roles of curcumin with the hope of recruiting curcumin as a therapeutic agent in future therapeutic regimen in order to enhance the efficacy of the treatment, as well as decreasing the adverse effects of synthetic chemical drugs.
\end{abstract}

Implication for health policy/practice/research/medical education:

This review revealed that curcumin treatment can be considered as a supplementary remedy for prevention of oxidative stress, inflammation, and immunomodulatory disorders. The literatures support the candidacy of this compound as a possible prospective natural drug and raise the possibility of recruiting curcumin in future therapeutic regimens.

Please cite this paper as: Boroumand N, Samarghandian S, Hashemy SI. Immunomodulatory, anti-inflammatory, and antioxidant effects of curcumin. J Herbmed Pharmacol. 2018;7(4):211-219. doi: 10.15171/jhp.2018.33.

\section{Introduction}

Turmeric is a widely used spice derived from the rhizomes of Curcuma longa which belongs to the ginger family (1). Having been used as a dietary spice, it has drawn scientists' attention to the possible medicinal benefits of its active compounds called curcuminoids which consist of curcumin, demethoxycurcumin and bisdemethoxycurcmin (2). Curcumin is the main active component of turmeric and the one which gives turmeric its yellow color. It was first introduced by Lampe and Milobedzka in 1910 (2,3). Considering a wide range of pharmacological properties that curcumin offers, numerous studies have investigated its potency as a therapeutic agent in various diseases. The conducted fundamental researches on cell cultures and animal models as well as pilot and clinical trials have provided strong evidence for heath promoting activities of this compound (4). Accordingly, it has been shown that curcumin could play pharmacological roles in various disorders such as autoimmune, cardiovascular, neoplastic, pulmonary, neurodegenerative and metabolic diseases (5). The therapeutic potential of curcumin have been also addressed in arthritis, some particular types of cancer, inflammatory bowel disease, chronic anterior uveitis, and pancreatitis (4). Indeed, several lines of evidence have signified antibacterial, antiviral, and antifungal properties of this compound (6). With regard to its wide array of health benefits and therapeutic roles, a single pathway appears unlikely to account for all these activities. With this concept, studies moved forward to investigate the underlying mechanisms contributing to the heath promoting properties of this compound. According to the conducted researches, it can be hypothesized that a complex interaction between three main events including 
inflammation, oxidative stress, and immunity is likely to contribute to different therapeutic roles of curcumin ( 7 , 8). Thus, in this review, the current knowledge on the anti-inflammatory, antioxidant, and immunomodulatory roles of curcumin is discussed with the hope of using curcumin as a therapeutic agent in future therapeutic regimens in order to not only enhance the efficacy of the treatment, but also to decrease the adverse effects of synthetic chemical drugs.

\section{Immunomodulatory effects}

The immune system has evolved to various specialized cells, and soluble molecules that are organized into a number of organs and tissues including bone marrow and thymus as the central lymphoid organs and lymph nodes, spleen as well as mucosal lymphoid tissues, as peripheral ones (9).

The immune response conceptually falls into 2 categories: innate and adaptive immunity. Innate immunity presents a stereotyped rapid response well before the evolution of antigen-specific responses provided by adaptive immunity (10). It is now apparent that curcumin could greatly affect both the innate and adaptive arms of immunity through modulating immune cells' function including neutrophils, macrophages, monocytes, natural killer cells (NK cells), dendritic cells (DCs), T cells, and B cells (11). This chapter provides an overview of the current knowledge on the immunomodulatory effects of curcumin on different principal effectors of immune system.

The activation, proliferation, and clonal expansion of T-lymphocytes occur by their initial encounter with antigens presented by antigen-presenting cells (12). The depletion or induction of lymphocytes proliferation has been frequently used as a criterion in evaluation of immunomodulatory effects of therapeutic agents and curcumin is no exception (13-16). In this view, several studies have investigated the effect of curcumin on proliferation of T-cells both ex-vivo and in-vivo. Some literatures revealed that following the induction of proliferation in $\mathrm{T}$ cells by a number of compounds such as phytohemagglutinin (PHA), concanavalin A (Con A), and phorbol-12-myristate-13-acetate (PMA), curcumin treatment could noticeably reduce the proliferation (17). However, contradictory data has been published regarding the anti-proliferative effect of curcumin on the T-lymphocytes, as some studies have signified its inductive effects. In this view, Gao et al. conducted a study presenting the wide-ranging functions of curcumin at different concentrations on murine splenic lymphocytes induced by conconavalin A (Con A), IL-2, or alloantigen. The results showed a rise in proliferation of Con A-induced cells at $6.25 \mu \mathrm{mol} / \mathrm{L}$ concentration of curcumin, while the proliferation decreased when $12.5 \mu \mathrm{mol} / \mathrm{L}$ curcumin was used. Furthermore, suppressed proliferative responses were observed at $25 \mu \mathrm{mol} / \mathrm{L}$ concentration of curcumin. With regard to IL-2 induced cells, curcumin showed an inhibitory dose dependent manner as the suppressive effect of curcumin on proliferation increased along with using higher concentration of this compound ranging from 6.25 to $25 \mu \mathrm{mol} / \mathrm{L}$. Meanwhile, the proliferation of alloantigen-induced spleen cells suppressed at $30 \mu \mathrm{mol} / \mathrm{L}$ curcumin. It is noteworthy that this inhibitory function of curcumin was shown to be irreversible (18). These data could suggest that the effect of curcumin on proliferation rate of $\mathrm{T}$ cells depends on both curcumin concentration and type of mitogen. However, the majority of published data are in favor of its inhibitory effects.

The inhibitory effect of curcumin on other immune cells proliferation has also become evident. Studies have shown that curcumin has suppressive effects on the proliferation of B-cell lymphoma cells. This function of curcumin followed a dose- and time-dependent pattern. Curcumin applied these effects by down-regulating the expression of growth and survival promoting genes including c-MYC, BCL-XL and NFkB (19). Coherently, a study on B-cell disorders and curcumin concluded that early intervention with this compound might delay the progression of early hematological malignancies including smoldering multiple myeloma, monoclonal gammopathy of undetermined significance, and stage $0 / 1$ chronic lymphocytic leukemia and prolong the survival of the patients. Interestingly, they revealed that curcumin causes no long-term toxicities even when it is taken over 5 years (20). In concurrence with this report, Haque et al suggested that curcumin treatment could be effective in treating $B$ cell autoimmune disease and reducing the chance for malignant transformation (21). In addition, it has been reported that curcumin could inhibit in vitro B-cell immortalization with EBV (22).

With regard to macrophages, it has been indicated that pre-incubation of these cells with $10 \mu \mathrm{M}$ curcumin completely suppressed the generation of superoxide anions, nitrite radical, as well as hydrogen peroxide in vitro. Furthermore, the rats fed with curcumin in addition to their typical diet (containing $8 \mathrm{wt} \%$ of coconut oil or cod liver oil or olive oil or peanut oil for 8 weeks) showed lower levels of reactive oxygen species (ROS) in their isolated peritoneal macrophages as compared with controls fed with the oil alone. Generally, it is concluded that administering curcumin in combination with dietary fatty acids reduces ROS generation in macrophages (23). In line with this study, Amano et al showed that liposomes containing curcumin could suppress the macrophages in mice in a selective manner (24). A pathway through which curcumin may exert its suppressive effects on macrophages has been suggested to be NF- $\mathrm{kB}$ signaling pathway as it has been observed that this compound diminishes macrophage activation and influenza virus induced-lung inflammation by inhibiting NF- $\kappa$ B pathway (25).

Not only curcumin could affect the proliferation and oxidative function of macrophages, but also it can influence their polarization via inhibiting TLR4- 
mediated pathway. A study on atheroprotective activity of curcumin in human acute monocytic leukemia THP-1 cells revealed that curcumin exerts aforementioned effects through its anti-inflammatory and atheroprotective properties (26). To further support the role of curcumin in immunomodulation, studies have found that there is a correlation between anti-inflammatory effects of curcumin and down-regulation of microRNA-155 in both LPS-treated macrophages and mice, suggesting that curcumin may mediate the suppression of LPS-induced inflammatory response through the inhibition of miR-155 (27).

Curcumin has also been shown to induce apoptosis and inhibit proliferation of a number of NK/T-cell lymphoma cell lines through mediating some related genes such as $\mathrm{NF} \kappa \mathrm{B}, \mathrm{Bcl}-\mathrm{xL}$, and cyclin D1. These results showed that curcumin could be used for inducing apoptosis even in chemoresistant lymphoma cell lines namely NK92 which may become a future therapeutic approach (28). Curcumin is also involved in mediating NK cells function by increasing nitric oxide (NO) generation in NK cells following prolonged treatment and enhancing their cytotoxicity $(7,29,30)$. It is noteworthy that the combined treatment of curcumin and omega- 3 fatty acids has shown to increase the NK cell-induced apoptosis of pancreatic cancer cells while curcumin alone could inhibit interferon- $\gamma$ production (31), presenting the dual function of curcumin which possibly could be highly dependent on its in vivo interactions .

Studies further investigated the effect of curcumin on DC function. Regarding surface molecules expression, curcumin noticeably blocked the expression of CD80, CD86, and MHC class II expression. Impaired production of some proinflammatory cytokines including IL1 $\beta$, IL6 and tumor necrosis factor (TNF)- $\alpha$ was also observed in curcumin-treated DCs. The phosphorylation of MAPK as well as translocation of NFKB was modulated by curcumin (32). These alterations in DC properties arises the question that whether curcumin modifies the physiological function of DC, for instance its antigen capture ability, or not. As further shown by Kim et al, interestingly, DC cells treated with curcumin showed high efficiency at Ag capturing (32). Furthermore, curcumin could affect DC function by arresting its maturation and inducing a tolerogenic phenotype through promoting the activity of FoxP3+ Tregs (33). The suggested pathways through which curcumin has been shown to suppress DCs activation in mice with experimental colitis are JAK/ STAT/SOCS signaling pathways (34). Moreover, It is held that curcumin could be applied as an immune suppressant as it has shown promise in preventing the response of human DC cells to immune stimulants (35).

The discussed data from both ex-vivo and in-vivo studies provide evidence on the inhibitory effects of curcumin on mentioned immune cells' proliferation and suppressing immune responses in some cases which could be beneficial in the treatment of autoimmune diseases. However, it has been shown that curcumin present anti-cancer activities through boosting the immune system. It is now apparent that tumor growth and survival results from the failure of immune surveillance processes in detecting and eliminating the cancer cells. Some factors causing this failure have shown to be low number of effector T cells (CD4+ and CD8+) as well as a shift from Th1-secreted cytokines to Th2 ones, which eventually results in diminishing the activity of cytotoxic T lymphocytes (CTLs) (36). In this regard, studies have shown that curcumin could restore the $\mathrm{CD}^{+}$and $\mathrm{CD}^{+}$ cells population, thereby re-establishing the shift towards a Th1-secreted cytokines again. It is worth noting that the loss of both central and memory $\mathrm{T}$ cell was prevented by curcumin (37). Coherently, tumor-bearing mice fed with curcumin showed a significant decrease in their tumor cell number. This reduction followed a dosedependent pattern. Indeed, curcumin reinstated the decreased immune cell number caused by cancer through preventing thymocytes and splenocytes from apoptosis (38). Curcumin is further involved in eliminating cancer by reducing the T-regulatory cell population, maintaining reactive oxygen and nitrogen production by macrophages, and NK cell cytotoxic activity $(30,39,40)$.

Despite the well-established anti-cancer role of curcumin, the observations regarding immune-suppressive effect of curcumin arises the question that how a compound could be both anti-cancer and immune-suppressive. The discussed findings suggest a dual role for curcumin as both inhibitor and inducer of proliferation in immunity cells. In fact it seems that curcumin shows distinct responses under different circumstances and adopts them according to the body condition. For instance in immunity cell cancers, namely lymphoma, as discussed earlier, curcumin presents inhibitory effects on that particular immune cells proliferation while in other type of cancer it increases the immune cells' proliferation to boost immune responses. However, further research is required to elucidate the exact mechanism or microenvironment condition which results in different responses of curcumin.

\section{Anti-inflammatory effects}

Curcumin was found to possess a miraculous power in anti-inflammatory processes. Various experimental and pharmacologic trials have signified its efficacy as an antiinflammatory agent (41). This property of curcumin has been shown to be mediated through down-regulating the activity of various signaling mediators including downregulation of COX-2 activity, mitogen-activated and Janus kinases, and inhibiting the generation of TNF-alpha, IL-1, $-2,-6,-8,-12$, and $5^{\prime}$-Adenosine monophosphate-activated protein kinase $(41,42)$. Recently, remarkable progress has been made in our understanding of the inflammatory mechanisms targeted by curcumin $(5,41,43)$. This chapter addresses the most pivotal mediators affected by this 
compound within the anti-inflammatory processes. To begin with, curcumin has been shown to be a potent blocker of inflammatory-induced NF- $\kappa$ B activation (44). $\mathrm{NF}-\kappa \mathrm{B}$ is a regulator of most mediators of inflammation ranging from chemokines and cytokines to adhesion molecules, kinases and enzymes (45). Curcumin suppresses NF- $\kappa \mathrm{B}$ activation by inhibiting I $\kappa \mathrm{B} \alpha$ kinase and AKT $(46,47)$. It is also suggested that curcumin targets NF- $\kappa B$ via its antioxidant activity. In this view, studies have shown that NF- $\mathrm{BB}$ DNA-binding activity is induced by oxidative stress, thus, antioxidant activity of curcumin might result in a depletion in NF- $\kappa$ B DNA-binding activity $(8,48)$. Curcumin is also believed to reduce the expression of the NF- $\kappa \mathrm{B}$-regulated gene products including IL-1, IL6, IL-8, cyclooxygenase-2 (COX-2), 5-LOX, MIP-1a, TNF, adhesion molecules, CXCR-4, c-reactive protein (CRP), etc (49-52). Likewise, COX-2 is believed to be involved in several inflammatory disorders through generating proinflammatory prostaglandins $(53,54)$. COX-2 inhibitors have also exhibited potential effects on treating the inflammatory diseases (55). There are inconclusive and contradictory findings regarding the effects of curcumin on COX-2 expression which add ambiguity to explain the underlying mechanisms of anti-inflammatory function of curcumin. Numerous published studies present that curcumin could suppress COX-2 expression (56-58), while others believe that it has a inducible effects $(59,60)$. However, the authors have shed light on this disparity between their findings by explaining that the response of malignant and transformed cells may be different from those of primary cells to curcumin treatment (60). Also, it has been suggested that curcumin with concentration higher than $10 \mu \mathrm{M}$ leads to suppression of COX-2, contrariwise, it acts as an inducible factor when it is imposed in lower doses $(58,60,61)$. Furthermore, regarding the exact target of curcumin in inhibiting the expression of COX-2, it is shown that curcumin treatment could inhibit the expression of COX-2 at both mRNA and protein levels $(60,62)$.

Besides COX-2, inducible nitric oxide synthase (iNOS) is also known to be implicated in inflammatory responses (63). Indeed, iNOS is reported to be another target for curcumin (64). iNOS results in NO generation, a wellknown pro-inflammatory mediator (65). Moreover, published studies have demonstrated that iNOS applies its anti-inflammatory function through the regulation of COX-2 and, thus, generating prostaglandins (66). Studies have shown that curcumin acts as an anti-inflammatory agent through inhibiting the NO generation as well as iNOS expression at both protein and mRNA levels $(67,68)$. Moreover, it has been shown that curcumin might downregulate the iNOS gene via suppression of c-Jun/ AP-1 activation (68).

The other target of curcumin in reducing inflammation is believed to be TNF. TNF has shown to exert pro- inflammatory effects through TNF receptor 2 (69). It has been suggested that curcumin could modulate the TNF- $\alpha$ associated inflammatory pathways (70). Some publications have shown that curcumin inhibits TNF production, but still, the exact underlying signaling are unclear $(51,70)$. Nevertheless, there are several possibilities regarding the TNF- $\alpha$ regulation by curcumin as presented by both in vitro and animal studies. For instance, it has been reported that curcumin could negatively regulate pro-inflammatory transcription factors including NF-kB, STAT proteins, and activator protein-1, thereby modulating TNF- $\alpha$ production (71). The interruption of signaling between TNF- $\alpha$ and its receptor by curcumin direct binding has also been suggested as another mechanism through which curcumin could suppress the inflammation induced by this cytokine (72).

In accordance with the investigations on inflammatory signaling mediators which curcumin targets, experimental studies have further proved the anti-inflammatory activity of this compound. In this aspect, animal studies on the effect of curcumin on inflammation have shown that administering curcumin could also inhibit in-vivo inflammation. In this regard, a study conducted on rat model of streptococcal cell wall-induced rheumatoid arthritis showed that injection of an extract containing curcuminoids prior to induction of arthritis prevented joint inflammation, remarkably (73). Curcumin also reduced inflammation in rat models of pancreatitis through suppressing NF- $\kappa \mathrm{B}$ and AP- 1 as well as decreasing TNF-a, IL-6, and iNOS in the pancreas, thereby an improvement in disease severity was observed (74).

Taken together, the discussed publications provide strong evidence for the anti-inflammatory properties of curcumin which might become as a simpler answer, in comparison with current therapies, to various inflammatory diseases.

\section{Antioxidant effects}

Curcumin is known for its antioxidant and radical scavenging properties. The unique chemical structure of this compound including its carbon-carbon double bonds, B-diketo group, and phenyl rings with hydroxyl and methoxy substituents has been proven to attribute to its antioxidant activity $(8,75)$. Scientists believe that the superb antioxidant features of curcumin are mainly due to its $\mathrm{H}$-atom donation from the phenolic group (76).

In recent years, there has been a particular interest in investigating scavenging properties of curcumin. Studies have shown that curcumin could scavenge free radicals efficiently (76,77). Besides, evidence demonstrated that curcumin is mainly involved in scavenging of these radicals in peroxidation processes. Therefore, possessing a great potency to inhibit lipid peroxidation, curcumin could protect cell membrane from oxidative damage by positioning itself within the cell membrane $(8,75)$. In this scenario, studies indicated that curcumin 
inhibits peroxidation mainly through its iron binding capacity (76). Curcumin also is considered as a potential antioxidant against hydrogen peroxide and superoxide radical generation (76).

The antioxidant properties of curcumin set up essential protective tasks for this compound specifically in reproductive system. For instance, it is well-understood that an appropriate balance between oxidant and antioxidant is a crucial factor for efficient performance of human reproductive system (78). Studies have shown that curcumin could protect structural integrity and functional activity of the spermatozoa particularly when oxidative damage to the germ cells is elevated. It could be explained by its phenol group which prevents oxidative cellular damage $(79,80)$. In accordance with this data earlier studies have shown that curcumin could have ameliorative effects on the both antioxidant status and activity of reproductive cells and tissues in mice treated with metronidazole (81). Considering more studies in this aspect, studies have reported that the balance between oxidant and antioxidant is often altered following cryopreservation of semen. Curcumin has been shown to preserve this balance by its antioxidant capacity (82). The stabilization of the total antioxidant equilibrium mediated by curcumin also results in protection of DNA integrity and viability in rat spermatozoa (82). Furthermore, it has been shown that treatment of spermatozoa with curcumin results in preservation of its motion, and preserves its mitochondrial as well as antioxidant characteristics, which are characterized by elevated superoxide dismutase (SOD), glutathione peroxidase (GPx), catalase (CAT) and glutathione (GSH) activities following curcumin treatment (83).

Curcumin was also shown to have potential effects on inhibiting oxidative damages caused by chronic stress in vital organs including brain, liver and kidney. It has been proven that curcumin plays this role through maintaining the SOD and GPx activity as well as reversing the stressinduced inhibition of CAT. These functions of curcumin may eventually result in a reduction in lipid peroxidation and, thus, ameliorate the detrimental effect of chronic stress on tissues (84).

Moreover, since oxidative stress is implicated in most of the neurodegenerative diseases, studies have investigated the possible protective effect of curcumin as an antioxidant, on astrocytes. In this regard, Daverey et al showed that curcumin not only inhibits the oxidative stress and its following adverse effects, but also protects astrocytes. Curcumin exhibited its antioxidant activity through ameliorating astrogliosis markers (GFAP and vimentin) and suppressing upregulation of Prdx6 induced by oxidative stress (85). In addition, treatment with curcumin results in recovery of the damaged mitochondria caused by oxidative stress (85). Furthermore, Wu et al demonstrated that curcumin treatment elevated both protein expression and enzyme activity of thioredoxin in rat cerebral cortical neurons, thus preserving them against cell injury (86). The antioxidant activity of this compound can be further confirmed by the study conducted by Suryanarayana et al who investigated the effect of curcumin administration on streptozotocin-induced hyperglycemic rat, as they showed elevated protein carbonyls, lipid peroxidation and altered activities of enzymatic antioxidant. Subsequently, administering curcumin and turmeric inhibits oxidative stress and reversed the altered balance (87).

It is worth noting that as discussed in the former section curcumin treatment suppressed the generation of superoxide anions, nitrite radical, as well as hydrogen peroxide in macrophages in vitro. This fact could be due to the antioxidant effects of curcumin. However, as macrophages use these oxidative mediators to combat the invader we could be facing a paradigm shift in how antioxidant activity of this compound should be viewed in inflammatory conditions particularly in terms of macrophages function. Beside this fact, in contrast to the traditional view of oxidative mediators, as a cause of tissue destruction and mediating inflammation, scientists have suggested that ROS are implicated in diminishing the inflammatory response. ROS also have been reported to be beneficial in autoimmune conditions (88). However, these hypotheses demand further support and are yet to be adequately understood since there are few studies discussing these issues, thus, it remains inconclusive.

\section{Conclusion}

In view of the discussed findings, future therapeutic approaches could rely on the ability of curcumin to prevent the oxidative stress, inflammation and immunomodulatory disorders. The literatures support the candidacy of this compound as a possible prospective natural drug and raise the possibility of recruiting curcumin in future therapeutic regimens. However, Additional studies and further investigations are needed to provide a better comprehension of the role of curcumin in prevention as well as treatment of the aforementioned disorders for better management of patients affected by these conditions. Moreover, the exact role of this compound as an antioxidant, anti-inflammatory and immunomodulatory agent should be well distinguished.

\section{Authors' contributions}

All the authors contributed to data collection and preparation of the manuscript. The first draft was prepared by NB. All authors read the final version and confirmed for the publication.

\section{Conflict of interest}

Authors declare there is not any conflict of interest.

\section{Ethical considerations}

Ethical issues including text plagiarism, misconduct, manipulation or appropriation, data fabrication, 
falsification, redundant publication as well as duplicate submissions have been carefully observed by authors.

\section{Funding/Support}

None.

\section{References}

1. Prasad S, Aggarwal BB. Turmeric, the Golden Spice: From Traditional Medicine to Modern Medicine. In: Benzie IFF, Wachtel-Galor S, eds. Herbal Medicine: Biomolecular and Clinical Aspects. 2nd ed. Boca Raton (FL): CRC Press/ Taylor \& Francis; 2011.

2. Ruby AJ, Kuttan G, Babu KD, Rajasekharan KN, Kuttan R. Anti-tumour and antioxidant activity of natural curcuminoids. Cancer Lett. 1995;94(1):79-83.

3. Lampe V, Milobedzka J, Kostanecki V. Structure of curcumin. Ber Dtsch Chem Ges. 1910;43:2163-70.

4. Jurenka JS. Anti-inflammatory properties of curcumin, a major constituent of Curcuma longa: a review of preclinical and clinical research. Altern Med Rev. 2009;14(2):141-53.

5. Aggarwal BB, Harikumar KB. Potential therapeutic effects of curcumin, the anti-inflammatory agent, against neurodegenerative, cardiovascular, pulmonary, metabolic, autoimmune and neoplastic diseases. Int J Biochem Cell Biol. 2009;41(1):40-59. doi: 10.1016/j.biocel.2008.06.010.

6. Zorofchian Moghadamtousi S, Abdul Kadir H, Hassandarvish P, Tajik H, Abubakar S, Zandi K. A review on antibacterial, antiviral, and antifungal activity of curcumin. Biomed Res Int. 2014;2014:186864. doi: $10.1155 / 2014 / 186864$.

7. Yadav VS, Mishra KP, Singh DP, Mehrotra S, Singh VK. Immunomodulatory effects of curcumin. Immunopharmacol Immunotoxicol. 2005;27(3):485-97. doi: $\quad 10.1080 / 08923970500242244$

8. Menon VP, Sudheer AR. Antioxidant and anti-inflammatory properties of curcumin. Adv Exp Med Biol. 2007;595:10525. doi: 10.1007/978-0-387-46401-5_3.

9. Janeway CA Jr, Travers P, Walport M, Shlomchik MJ. The components of the immune system. In: Immunobiology: The Immune System in Health and Disease. 5th ed. New York: Garland Science; 2001.

10. Chaplin DD. Overview of the immune response. J Allergy Clin Immunol. 2010;125(2 Suppl 2):S3-23. doi: 10.1016/j. jaci.2009.12.980.

11. Srivastava RM, Singh S, Dubey SK, Misra K, Khar A. Immunomodulatory and therapeutic activity of curcumin. Int Immunopharmacol. 2011;11(3):331-41. doi: 10.1016/j. intimp.2010.08.014.

12. Grossi CE, Ciccone E, Tacchetti C, Santoro G, Anastasi G. Anatomy of the immune system: facts and problems. Ital J Anat Embryol. 2000;105(4):97-124.

13. Mello KF, Lunardelli A, Donadio MVF, Caberlon E, de Oliveira CS, Bastos CM, et al. Immunomodulatory effects of oral antidiabetic drugs in lymphocyte cultures from patients with type 2 diabetes. J Bras Patol Med Lab. 2011;47(1):43-8. doi: 10.1590/S1676-24442011000100006.

14. Cho JY. Immunomodulatory effect of nonsteroidal antiinflammatory drugs (NSAIDs) at the clinically available doses. Arch Pharm Res. 2007;30(1):64-74.

15. Andjelkovic Z, Vojinovic J, Pejnovic N, Popovic M,
Dujic A, Mitrovic D, et al. Disease modifying and immunomodulatory effects of high dose 1 alpha $(\mathrm{OH})$ D3 in rheumatoid arthritis patients. Clin Exp Rheumatol. 1999;17(4):453-6.

16. Gautam SC, Gao X, Dulchavsky S. Immunomodulation by curcumin. Adv Exp Med Biol. 2007;595:321-41. doi: 10.1007/978-0-387-46401-5_14.

17. Ranjan D, Chen C, Johnston TD, Jeon H, Nagabhushan M. Curcumin inhibits mitogen stimulated lymphocyte proliferation, NFkappaB activation, and IL-2 signaling. J Surg Res. 2004;121(2):171-7. doi: 10.1016/j.jss.2004.04.004.

18. Gao X, Kuo J, Jiang H, Deeb D, Liu Y, Divine G, et al. Immunomodulatory activity of curcumin: suppression of lymphocyte proliferation, development of cellmediated cytotoxicity, and cytokine production in vitro. Biochem Pharmacol. 2004;68(1):51-61. doi: 10.1016/j. bcp.2004.03.015.

19. Han SS, Chung ST, Robertson DA, Ranjan D, Bondada S. Curcumin causes the growth arrest and apoptosis of B cell lymphoma by downregulation of egr-1, c-myc, bcl-XL, NFkappa B, and p53. Clin Immunol. 1999;93(2):152-61. doi: 10.1006/clim.1999.4769.

20. Golombick T, Diamond TH, Manoharan A, Ramakrishna R. B-Cell Disorders and Curcumin. Integr Cancer Ther. 2017;16(3):255-7. doi: 10.1177/1534735415622013.

21. Haque S, Lee H, Waqas B, Chiorazzi N, Mongini P. Antiinflammatory curcumin inhibits AID expression within cycling human B cells (96.21). Am Assoc Immnol. 2010; 25(1): 1-5.

22. Ranjan D, Siquijor A, Johnston TD, Wu G, Nagabhuskahn M. The effect of curcumin on human B-cell immortalization by Epstein-Barr virus. Am Surg. 1998;64(1):47-51; discussion -2 .

23. Joe B, Lokesh BR. Role of capsaicin, curcumin and dietary n-3 fatty acids in lowering the generation of reactive oxygen species in rat peritoneal macrophages. Biochim Biophys Acta. 1994;1224(2):255-63.

24. Amano C, Minematsu H, Fujita K, Iwashita S, Adachi M, Igarashi $\mathrm{K}$, et al. Nanoparticles Containing Curcumin Useful for Suppressing Macrophages In Vivo in Mice. PLoS One. 2015;10(9):e0137207. doi: 10.1371/journal. pone.0137207.

25. Xu Y, Liu L. Curcumin alleviates macrophage activation and lung inflammation induced by influenza virus infection through inhibiting the NF-kappaB signaling pathway. Influenza Other Respir Viruses. 2017;11(5):457-63. doi: 10.1111/irv.12459.

26. Zhou Y, Zhang T, Wang X, Wei X, Chen Y, Guo L, et al. Curcumin Modulates Macrophage Polarization Through the Inhibition of the Toll-Like Receptor 4 Expression and its Signaling Pathways. Cell Physiol Biochem. 2015;36(2):63141. doi: 10.1159/000430126.

27. Ma F, Liu F, Ding L, You M, Yue H, Zhou Y, et al. Antiinflammatory effects of curcumin are associated with down regulating microRNA-155 in LPS-treated macrophages and mice. Pharm Biol. 2017;55(1):1263-73. doi: 10.1080/13880209.2017.1297838.

28. Kim K, Ryu K, Ko Y, Park C. Effects of nuclear factorkappaB inhibitors and its implication on natural killer T-cell lymphoma cells. Br J Haematol. 2005;131(1):59-66. doi: $\quad 10.1111 /$ j.1365-2141.2005.05720.x. 
29. Bhaumik S, Jyothi MD, Khar A. Differential modulation of nitric oxide production by curcumin in host macrophages and NK cells. FEBS Lett. 2000;483(1):78-82.

30. Varalakshmi C, Ali AM, Pardhasaradhi BV, Srivastava RM, Singh S, Khar A. Immunomodulatory effects of curcumin: in-vivo. Int Immunopharmacol. 2008;8(5):688-700. doi: 10.1016/j.intimp.2008.01.008.

31. Fiala M. Curcumin and omega-3 fatty acids enhance NK cell-induced apoptosis of pancreatic cancer cells but curcumin inhibits interferon-gamma production: benefits of omega-3 with curcumin against cancer. Molecules. 2015;20(2):3020-6. doi: 10.3390/molecules20023020.

32. Kim GY, Kim KH, Lee SH, Yoon MS, Lee HJ, Moon DO, et al. Curcumin inhibits immunostimulatory function of dendritic cells: MAPKs and translocation of NF-kappa B as potential targets. J Immunol. 2005;174(12):8116-24.

33. Rogers NM, Kireta S, Coates PT. Curcumin induces maturation-arrested dendritic cells that expand regulatory T cells in vitro and in vivo. Clin Exp Immunol. 2010;162(3):460-73. doi: 10.1111/j.1365-2249.2010.04232.x.

34. Zhao HM, Xu R, Huang XY, Cheng SM, Huang MF, Yue HY, et al. Curcumin Suppressed Activation of Dendritic Cells via JAK/STAT/SOCS Signal in Mice with Experimental Colitis. Front Pharmacol. 2016;7:455. doi: 10.3389/ fphar.2016.00455.

35. Shirley SA, Montpetit AJ, Lockey RF, Mohapatra SS. Curcumin prevents human dendritic cell response to immune stimulants. Biochem Biophys Res Commun. 2008;374(3):431-6. doi: 10.1016/j.bbrc.2008.07.051.

36. Wang Q, Redovan C, Tubbs R, Olencki T, Klein E, Kudoh $S$, et al. Selective cytokine gene expression in renal cell carcinoma tumor cells and tumor-infiltrating lymphocytes. Int J Cancer. 1995;61(6):780-5.

37. Bhattacharyya S, Md Sakib Hossain D, Mohanty S, Sankar Sen G, Chattopadhyay S, Banerjee S, et al. Curcumin reverses $\mathrm{T}$ cell-mediated adaptive immune dysfunctions in tumor-bearing hosts. Cell Mol Immunol. 2010;7(4):306-15. doi: $10.1038 / \mathrm{cmi} .2010 .11$

38. Pal S, Bhattacharyya S, Choudhuri T, Datta GK, Das T, Sa G. Amelioration of immune cell number depletion and potentiation of depressed detoxification system of tumor-bearing mice by curcumin. Cancer Detect Prev. 2005;29(5):470-8. doi: 10.1016/j.cdp.2005.05.003.

39. Zhao GJ, Lu ZQ, Tang LM, Wu ZS, Wang DW, Zheng JY, et al. Curcumin inhibits suppressive capacity of naturally occurring CD4+CD25+ regulatory $\mathrm{T}$ cells in mice in vitro. Int Immunopharmacol. 2012;14(1):99-106. doi: 10.1016/j. intimp.2012.06.016.

40. Bose S, Panda AK, Mukherjee S, Sa G. Curcumin and tumor immune-editing: resurrecting the immune system. Cell Div. 2015;10:6. doi: 10.1186/s13008-015-0012-z.

41. Fadus MC, Lau C, Bikhchandani J, Lynch HT. Curcumin: An age-old anti-inflammatory and anti-neoplastic agent. J Tradit Complement Med. 2017;7(3):339-46. doi: 10.1016/j. jtcme.2016.08.002.

42. Soltani A, Salmaninejad A, Jalili-Nik M, Soleimani A, Javid H, Hashemy SI, et al. 5'-Adenosine monophosphateactivated protein kinase: A potential target for disease prevention by curcumin. J Cell Physiol. 2018. doi: 10.1002/ jcp. 27192

43. Hewlings SJ, Kalman DS. Curcumin: A Review of Its'
Effects on Human Health. Foods. 2017;6(10). doi: 10.3390/ foods6100092.

44. Kim JH, Gupta SC, Park B, Yadav VR, Aggarwal BB. Turmeric (Curcuma longa) inhibits inflammatory nuclear factor (NF)-kappaB and NF-kappaB-regulated gene products and induces death receptors leading to suppressed proliferation, induced chemosensitization, and suppressed osteoclastogenesis. Mol Nutr Food Res. 2012;56(3):454-65. doi: $10.1002 / \mathrm{mnfr} .201100270$.

45. Tak PP, Firestein GS. NF-kappaB: a key role in inflammatory diseases. J Clin Invest. 2001;107(1):7-11. doi: 10.1172/ jcil1830.

46. Deeb D, Jiang H, Gao X, Al-Holou S, Danyluk AL, Dulchavsky SA, et al. Curcumin [1,7-bis(4-hydroxy-3methoxyphenyl)-1-6-heptadine-3,5-dione; C21H20O6] sensitizes human prostate cancer cells to tumor necrosis factor-related apoptosis-inducing ligand/Apo2L-induced apoptosis by suppressing nuclear factor-kappaB via inhibition of the prosurvival Akt signaling pathway. J Pharmacol Exp Ther. 2007;321(2):616-25. doi: 10.1124/ jpet.106.117721.

47. Aggarwal S, Ichikawa H, Takada Y, Sandur SK, Shishodia S, Aggarwal BB. Curcumin (diferuloylmethane) downregulates expression of cell proliferation and antiapoptotic and metastatic gene products through suppression of IkappaBalpha kinase and Akt activation. Mol Pharmacol. 2006;69(1):195-206. doi: 10.1124/mol.105.017400.

48. Singh S, Aggarwal BB. Activation of transcription factor NF-kappa B is suppressed by curcumin (diferuloylmethane) [corrected]. J Biol Chem. 1995;270(42):24995-5000.

49. Skommer J, Wlodkowic D, Pelkonen J. Gene-expression profiling during curcumin-induced apoptosis reveals downregulation of CXCR4. Exp Hematol. 2007;35(1):8495. doi: 10.1016/j.exphem.2006.09.006.

50. Shakibaei M, Schulze-Tanzil G, John T, Mobasheri A. Curcumin protects human chondrocytes from ILl1beta-induced inhibition of collagen type II and beta1integrin expression and activation of caspase-3: an immunomorphological study. Ann Anat. 2005;187(56):487-97.

51. Shishodia S, Amin HM, Lai R, Aggarwal BB. Curcumin (diferuloylmethane) inhibits constitutive NF-kappaB activation, induces G1/S arrest, suppresses proliferation, and induces apoptosis in mantle cell lymphoma. Biochem Pharmacol. 2005;70(5):700-13. doi: 10.1016/j. bcp.2005.04.043.

52. Li L, Aggarwal BB, Shishodia S, Abbruzzese J, Kurzrock R. Nuclear factor-kappaB and IkappaB kinase are constitutively active in human pancreatic cells, and their down-regulation by curcumin (diferuloylmethane) is associated with the suppression of proliferation and the induction of apoptosis. Cancer. 2004;101(10):2351-62. doi: 10.1002/cncr.20605.

53. Chen C. COX-2's new role in inflammation. Nat Chem Biol. 2010;6(6):401-2. doi: 10.1038/nchembio.375.

54. Wang D, Dubois RN. The role of COX-2 in intestinal inflammation and colorectal cancer. Oncogene. 2010;29(6):781-8. doi: 10.1038/onc.2009.421.

55. Ricciotti E, FitzGerald GA. Prostaglandins and inflammation. Arterioscler Thromb Vasc Biol. 2011;31(5):986-1000. doi: 10.1161/atvbaha.110.207449. 56. Soetikno V, Sari FR, Lakshmanan AP, Arumugam S, 
Harima M, Suzuki K, et al. Curcumin alleviates oxidative stress, inflammation, and renal fibrosis in remnant kidney through the Nrf2-keap1 pathway. Mol Nutr Food Res. 2013;57(9):1649-59. doi: 10.1002/mnfr.201200540.

57. Moon DO, Kim MO, Choi YH, Park YM, Kim GY. Curcumin attenuates inflammatory response in IL-1beta-induced human synovial fibroblasts and collagen-induced arthritis in mouse model. Int Immunopharmacol. 2010;10(5):60510. doi: 10.1016/j.intimp.2010.02.011.

58. Lee KW, Kim JH, Lee HJ, Surh YJ. Curcumin inhibits phorbol ester-induced up-regulation of cyclooxygenase-2 and matrix metalloproteinase- 9 by blocking ERK1/2 phosphorylation and NF-kappaB transcriptional activity in MCF10A human breast epithelial cells. Antioxid Redox Signal. 2005;7(11-12):1612-20. doi: 10.1089/ ars.2005.7.1612.

59. Hong J, Bose M, Ju J, Ryu JH, Chen X, Sang S, et al. Modulation of arachidonic acid metabolism by curcumin and related beta-diketone derivatives: effects on cytosolic phospholipase A(2), cyclooxygenases and 5-lipoxygenase. Carcinogenesis. 2004;25(9):1671-9. doi: 10.1093/carcin/ bgh 165.

60. Tan X, Poulose EM, Raveendran VV, Zhu BT, Stechschulte DJ, Dileepan KN. Regulation of the expression of cyclooxygenases and production of prostaglandin I(2) and $\mathrm{E}(2)$ in human coronary artery endothelial cells by curcumin. J Physiol Pharmacol. 2011;62(1):21-8.

61. Binion DG, Otterson MF, Rafiee P. Curcumin inhibits VEGF-mediated angiogenesis in human intestinal microvascular endothelial cells through COX-2 and MAPK inhibition. Gut. 2008;57(11):1509-17. doi: 10.1136/ gut.2008.152496.

62. Cho JW, Park K, Kweon GR, Jang BC, Baek WK, Suh MH, et al. Curcumin inhibits the expression of COX-2 in UVBirradiated human keratinocytes ( $\mathrm{HaCaT}$ ) by inhibiting activation of AP-1: p38 MAP kinase and JNK as potential upstream targets. Exp Mol Med. 2005;37(3):186-92. doi: 10.1038/emm.2005.25.

63. Cassini-Vieira P, Araujo FA, da Costa Dias FL, Russo RC, Andrade SP, Teixeira MM, et al. iNOS Activity Modulates Inflammation, Angiogenesis, and Tissue Fibrosis in Polyether-Polyurethane Synthetic Implants. Mediators Inflamm. 2015;2015:138461. doi: 10.1155/2015/138461.

64. Song MY, Yim JY, Yim JM, Kang IJ, Rho HW, Kim HS, et al. Use of curcumin to decrease nitric oxide production during the induction of antitumor responses by IL-2. J Immunother. 2011;34(2):149-64.doi:10.1097/CJI.0b013e3182056ec4.

65. Forstermann U, Sessa WC. Nitric oxide synthases: regulation and function. Eur Heart J. 2012;33(7):829-37, 37a-37d. doi: 10.1093/eurheartj/ehr304.

66. Landino LM, Crews BC, Timmons MD, Morrow JD, Marnett LJ. Peroxynitrite, the coupling product of nitric oxide and superoxide, activates prostaglandin biosynthesis. Proc Natl Acad Sci U S A. 1996;93(26):15069-74.

67. Kaewsamut B, Pinlaor S, Boonmars T, Srisawangwong T, Yongvanit $\mathrm{P}$. Effect of curcumin on the inducible nitric oxide synthase (iNOS) and antioxidant enzyme expression in hamsters infected with Opisthorchis viverrini. Southeast Asian J Trop Med Public Health. 2007;38(suppl 1):66-73.

68. Brouet I, Ohshima H. Curcumin, an anti-tumour promoter and anti-inflammatory agent, inhibits induction of nitric oxide synthase in activated macrophages. Biochem Biophys Res Commun. 1995;206(2):533-40.

69. Masli S, Turpie B. Anti-inflammatory effects of tumour necrosis factor (TNF)-alpha are mediated via TNF-R2 (p75) in tolerogenic transforming growth factor-beta-treated antigen-presenting cells. Immunology. 2009;127(1):62-72. doi: 10.1111/j.1365-2567.2008.02933.x.

70. Sahebkar A, Cicero AFG, Simental-Mendia LE, Aggarwal BB, Gupta SC. Curcumin downregulates human tumor necrosis factor-alpha levels: A systematic review and metaanalysis ofrandomized controlled trials. Pharmacol Res. 2016;107:234-42. doi: 10.1016/j.phrs.2016.03.026.

71. Shishodia S, Singh T, Chaturvedi MM. Modulation of transcription factors by curcumin. Adv Exp Med Biol. 2007;595:127-48. doi: 10.1007/978-0-387-46401-5_4.

72. Gupta SC, Prasad S, Kim JH, Patchva S, Webb LJ, Priyadarsini IK, et al. Multitargeting by curcumin as revealed by molecular interaction studies. Nat Prod Rep. 2011;28(12):1937-55. doi: 10.1039/c1np00051a.

73. Funk JL, Oyarzo JN, Frye JB, Chen G, Lantz RC, Jolad $\mathrm{SD}$, et al. Turmeric extracts containing curcuminoids prevent experimental rheumatoid arthritis. J Nat Prod. 2006;69(3):351-5. doi: 10.1021/np050327j.

74. Gukovsky I, Reyes CN, Vaquero EC, Gukovskaya AS, Pandol SJ. Curcumin ameliorates ethanol and nonethanol experimental pancreatitis. Am J Physiol Gastrointest Liver Physiol. 2003;284(1):G85-95. doi: 10.1152/ ajpgi.00138.2002.

75. Wright JS. Predicting the antioxidant activity of curcumin and curcuminoids. J Mol Struct. 2002;591(1-3):207-17. doi: 10.1016/S0166-1280(02)00242-7.

76. Ak T, Gulcin I. Antioxidant and radical scavenging properties of curcumin. Chem Biol Interact. 2008;174(1):2737. doi: 10.1016/j.cbi.2008.05.003.

77. Borra SK, Gurumurthy P, Mahendra J. Antioxidant and free radical scavenging activity of curcumin determined by using different in vitro and ex vivo models. J Med Plant Res. 2013;7(36):2680-90.

78. Agarwal A, Saleh RA, Bedaiwy MA. Role of reactive oxygen species in the pathophysiology of human reproduction. Fertil Steril. 2003;79(4):829-43.

79. Azza M, El-Wakf AM, Elhabiby ES, El-kholy WM, ElGhany EA. Use of tumeric and curcumin to alleviate adverse reproductive outcomes of water: Nitrate pollution in male rats. Nat Sci Sleep. 2011;9(7):229-39.

80. Galano A, Álvarez-Diduk R, Ramírez-Silva MT, AlarcónÁngeles G, Rojas-Hernández A. Role of the reacting free radicals on the antioxidant mechanism of curcumin. Chemical Physics. 2009;363(1-3):13-23.

81. Karbalay-Doust S, Noorafshan A. Ameliorative effects of curcumin on the spermatozoon tail length, count, motility and testosterone serum level in metronidazole-treated mice. Prague Med Rep. 2011;112(4):288-97.

82. Soleimanzadeh A, Saberivand A. Effect of curcumin on rat sperm morphology after the freeze-thawing process. Veterinary Research Forum; 2013.

83. Tvrdá E, Tušimová E, Kováčik A, et al. Curcumin has protective and antioxidant properties on bull spermatozoa subjected to induced oxidative stress. Animal Reproduction 
Science. 2016;172:10-20.

84. Samarghandian S, Azimi-Nezhad M, Farkhondeh T, Samini F. Anti-oxidative effects of curcumin on immobilizationinduced oxidative stress in rat brain, liver and kidney. Biomed Pharmacother. 2017;87:223-9.

85. Daverey A, Agrawal SK. Curcumin alleviates oxidative stress and mitochondrial dysfunction in astrocytes. Neuroscience. 2016;333:92-103.

86. Wu JX, Zhang LY, Chen YL, Yu SS, Zhao Y, Zhao J. Curcumin pretreatment and post-treatment both improve the antioxidative ability of neurons with oxygen-glucose deprivation. Neural Regen Res. 2015;10(3):481.

87. Suryanarayana P, Satyanarayana A, Balakrishna N, Kumar PU, Reddy GB. Effect of turmeric and curcumin on oxidative stress and antioxidant enzymes in streptozotocininduced diabetic rat. Med Sci Monit. 2007;13(12):BR286BR92.

88. Hultqvist M, Olsson LM, Gelderman KA, Holmdahl R. The protective role of ROS in autoimmune disease. Trends Immunol. 2009;30(5):201-8. 